\title{
Effect of Conservational and Conventional Tillage Systems on Functional Soil Archaea Diversity in Wheat-Pea Rotation Field
}

\author{
E. Essel ${ }^{1,2,4}$, Lingling $\mathrm{Li}^{1,2}$, Chaochao Deng ${ }^{1,2}$, Junhong Xie ${ }^{1,2}$, Renzhi Zhang ${ }^{1,3}$, Zhuzhu Luo ${ }^{1,3}$ \& Liqun Cai ${ }^{1,3}$ \\ ${ }^{1}$ Gansu Provincial Key Lab of Arid Land Crop Science, Lanzhou, China \\ ${ }^{2}$ College of Agronomy, Gansu Agricultural University, Lanzhou, China \\ ${ }^{3}$ College of Resources and Environmental Sciences, Gansu Agricultural University, Lanzhou, China \\ ${ }^{4}$ Department of Applied Biology, University for Development Studies, Tamale, Ghana \\ Correspondence: Lingling Li, College of Agronomy, Gansu Agricultural University, No.1 Yingmencun, Anning \\ District, Lanzhou 730070, China. Tel: 86-931-760-3751. E-mail: lill@gsau.edu.cn
}

Received: August 20,2017 $\quad \begin{aligned} & \text { Accepted: September 18, } 2017 \quad \text { Online Published: October 15, } 2017 \\ & \text { doi:10.5539/jas.v9n11p34 }\end{aligned}$ URL: https://doi.org/10.5539/jas.v9n11p34

The research is financed by the National Natural Science Foundation of China (31460337, 31660373 and 3171101272), The 'National Twelfth Five-Year Plan' Circular Agricultural Science and Technology Project (2012 BAD14B03), Education Department of Gansu Province (2017C-12) and Gansu Provincial Key Laboratory of Aridland Crop Science open fund project (GSCS-2013-13).

\begin{abstract}
Soil borne archaea in agricultural systems is crucial for cycling of nutrient such as Nitrogen, Carbon and Sulphur. The objective of the study was to assess the effect of different tillage systems on functional archaea diversity in a 15 years cereal-legume rotation field using Illumina sequencing platform for archaea 16S rRNA gene. The treatments in the study included conventional tillage with stubble removed (T), no-till with stubble removed (NT), conventional tillage with stubble incorporated (TS) and no-till with stubble retained (NTS). The results showed that the dominant soil archaea phyla was Crenarchaeota $(>96 \%)$, followed by Euryarchaeota with a lower abundance of $<3 \%$ and then Parvarchaeota and other bacteria phyla made up $<1 \%$ across the treatments and depths. The treatment means were ranked as NT $>$ NTS $>$ TS $>$ T for 16S rRNA number of OTUs, Shannon and Simpson indices calculated for the $0-10 \mathrm{~cm}$ soil depth. Analysis of factor effect revealed that tillage but not stubble retention or their interaction significantly influenced $(\mathrm{P}<0.01$ and $\mathrm{P}<0.05) 16 \mathrm{~S}$ rRNA diversity. Non metric Multidimensional Scaling (NMDS) analysis clearly grouped the microbial communities according to depths. Linear Discriminant Analysis Effect Size (LEfSe) identified Crenarchaeota and Thaumarchaeota (to genus level) as significantly enriched clades in $0-10 \mathrm{~cm}$ depth of T while Euryarchaeota and Thermoplasmata were significantly enriched in TS. The conservational tillage systems (NT and NTS) promoted even distribution of archaea diversity while conventional tillage systems (T and TS) enriched the archaea communities identified in the study.
\end{abstract}

Keywords: 16S rRNA gene, Archaea diversity, stubble retention, tillage systems

\section{Introduction}

Archaea constitutes a domain of microbes that exhibit diverse functional metabolic activity, habitat and typically adapted to chronic energy stress conditions than bacteria (Swan \& Valentine, 2009). Archaea may obtain their source of energy from inorganic compounds such as ammonia or sulfur, use sunlight as a source of energy in non-oxygen-generating photosynthesis, or by autotrophic fixation of atmospheric $\mathrm{CO}_{2}$ as a source of carbon (Pratscher et al., 2011; Zhalnina et al., 2012). However, their utilization of organic carbon source is still inadequately understood (Zhalnina et al., 2012). In non-extreme terrestrial environment such as agricultural soil, archaea play crucial functional roles in the cycling of nutrients such as carbon, nitrogen and sulphur (Jarrell et al., 2011) but also have the potential to contribute to atmospheric greenhouse gas emission (Offre et al., 2013). For instance, in the carbon cycle, methanogenesis and anaerobic methane oxidation are important intermediate steps that are performed exclusively by anaerobic Euryarchaeota and Methanomicrobia respectively (Offre et al., 2013). Also in the nitrogen cycle, Crenarchaeota (Thaumarchaeota and Candidatus Nitrososphaera) are reported 
to be involved in fixation of dinitrogen $\left(\mathrm{N}_{2}\right)$ gas, oxidation of ammonia to nitrite, and denitrification (Taylor et al., 2010).

The 16S rRNA marker gene has become the gold standard in molecular identification of archaea and bacteria diversity (Case et al., 2007). These small subunit ribosomal RNA genes are universally present in archaea and bacteria and contain both highly conserved fragments and variable regions that allow for the discrimination of different taxonomic levels (Vos et al., 2012). Illumina high-throughput sequencing platform has been employed to study microbial community composition and is reported to be accurate and rapid in the identification than traditional methods such as culture and serial dilution methods, Biolog system and biomarkers which often isolate only a few soil microbes (Klingler et al., 1992). Soil archaea are difficult to culture but molecular methods have been used to demonstrate the presence of archaeal 16S rRNA gene sequences in agricultural, grassland and forest soils (Navarrete et al., 2011).

In agricultural fields, tillage practices negatively affect soil chemical, physical and biological properties by exacerbating soil degradation which may consequently trigger changes in the soil microbial community structure and composition (Dorr de Quadros et al., 2012). It is widely accepted that no-till, residue retention, cover crops and crop rotations are conservation agriculture practices that protect soil, water, nutrients and increase microbial activity and biomass (Feng, 2003). However, varying research outcomes have been reported (Kaurin et al., 2015; Dong et al., 2017) making specific impacts of conservation agriculture practices on soil bacteria and archaea particularly complex to explain (Ng et al., 2012).

In the western Loess Plateau of China, conventional and traditional methods of soil preparation, application of Nitrogen fertilizers (Fan et al., 2005) and consistent crop residues removal from the fields are common farming practices (Lamptey et al., 2017) for the production of crops such winter and spring wheat, maize, soybean, potato among others (Nolan et al., 2008). These practices have worsened soil degradation processes, contributed to the decline of soil carbon and fertility (Zhang et al., 2016) and therefore, may impact microbial community structure. Conservation tillage techniques have been employed to improve soil physicochemical properties and greenhouse gas emissions for sustainable cultivation of spring wheat and field pea (Huang et al., 2013; Yeboah et al., 2016a, 2016b; Yeboah et al., 2017) but the rate of adoption is still relatively low in the region. The impact of tillage practices on soil archaea community structure has received low specialised research attention in the study area. Therefore, the study hypothesized that withdrawal of tillage and retention of stubble from previous crops in rotation systems will influence functional soil archaea diversity. We set out an objective to investigate the effect of different tillage systems on functional archaea communities in the 15 years crop rotation field using the $16 \mathrm{~S}$ rRNA marker gene.

\section{Materials and Methods}

\subsection{Site Description}

The study was carried out in the Rainfed Agricultural Experimental Station of the Gansu Agricultural University $\left(35^{\circ} 28^{\prime} \mathrm{N}, 104^{\circ} 44^{\prime} \mathrm{E}\right.$, elevation $1971 \mathrm{~m}$ above sea level), Dingxi, Gansu Province, Northwest China. The soil type in the site has a sandy loam texture with $\geq 50 \%$ sand and is locally known as Huangmian (Chinese Soil Taxonomy Cooperative Research Group, 1995), which is equated to the Calcaric Cambisol by the FAO soil classification (1990). The soil has organic matter content of $<14.75 \mathrm{~g} / \mathrm{kg}(<1.48 \%)$ and an average $\mathrm{pH}$ of about 8.44. The annual temperature ranges between $-22-38{ }^{\circ} \mathrm{C}$ in January and July respectively while the average long-term annual rainfall in the area is $390.7 \mathrm{~mm}$ per year.

\subsection{Design of Experiment}

This research was carried out in 2016 on a long-term field experiment which was initiated in 2001. Before then, the site had a long history of conventional tillage and continuous cropping of flax (Linum usitatissimum L.). The experiment is a two factorial design with two phases of rotation and four tillage treatments (Table 1) arranged in a randomised complete block design with three replicates. Spring wheat (cv. Dingxi No. 35) and Field pea (cv. Yannong) were sown in rotation with both phases represented in each year for the past 15 years and is also known as double sequence rotation $(\mathrm{W} \rightarrow \mathrm{P} \rightarrow \mathrm{W}$ and $\mathrm{P} \rightarrow \mathrm{W} \rightarrow \mathrm{P}$ sequence). The crop rotation started with spring wheat in the first phase, followed by field pea while the second phase started with field pea followed by spring wheat in that sequence each year for the past 15 years. In conventional tillage $(T)$ plots, all the stubbles were removed before ploughing to a depth of 10-20 cm. Conventional tillage with stubble incorporated (TS) plots had all stubbles from the previous crop returned to those same plots after threshing and then incorporated into the soil during ploughing. In the No-till (NT) treatment plots, no ploughing was performed and all the stubbles were removed at harvest whiles in No-till with stubble retained (NTS) plots, all the stubbles from the previous crops were returned to the original plots and retained on the surface of the soil. 
Table 1. Treatment codes and names

\begin{tabular}{ll}
\hline Treatments code & Treatment Name \\
\hline T & Conventional tillage with stubble removed \\
NT & No-till with stubble removed \\
TS & Conventional tillage with stubble incorporated \\
NTS & No-till with stubble retained \\
\hline
\end{tabular}

Each year, spring wheat was cultivated in early March at a rate of $187.5 \mathrm{~kg} \mathrm{ha}^{-1}$ with a row spacing of $20 \mathrm{~cm}$ and harvested in late July to early August. Field Pea is sown in early April at a rate of $180 \mathrm{~kg} \mathrm{ha}^{-1}$ with a row spacing of $24 \mathrm{~cm}$ and harvested in early July each year. Low rates of Nitrogen and Phosphorus fertilizers are applied at sowing with the no-till seeder at a rate of $105 \mathrm{~kg} \mathrm{~N} / \mathrm{ha}$ as urea $(46 \% \mathrm{~N}), 45.9 \mathrm{~kg}$ P/ha as calcium superphosphate $(6.1 \% \mathrm{P})$ for spring wheat, $20 \mathrm{~kg} \mathrm{~N} / \mathrm{ha}$ and $45.9 \mathrm{~kg} \mathrm{P} / \mathrm{ha}$ for field pea.

\subsection{Soil Sampling}

Soil samples were collected before seeding the field Pea phase of the experiment in April for the 2016 planting season. At sampling, three soil cores samples were randomly collected from each plot at the depth of $0-10 \mathrm{~cm}$ and $10-30 \mathrm{~cm}$. The three soil cores from each plot were pooled to form a composite sample which was further divided into subsamples. The subsamples were stored on dry ice, conveyed to the laboratory and stored at $-80{ }^{\circ} \mathrm{C}$ for molecular analysis.

\subsection{Soil DNA Extraction and Amplification}

Genomic DNA extraction from soil samples was done by the use MoBio PowerSoil $®$ DNA Isolation Kit (MoBio Laboratories, Solana Beach, CA, USA) following the manufacturer's instructions. PCR amplification of V3-V4 of 16S rRNA (480bp with barcode) was executed using the primers 338F 5'-ACTCCTACGGGAGGCAGCA-3' and 806R 5'-GGACTACHVGGGTWTCTAAT-3' to identify archaea genes. Nanodrop 2000 Spectrophotometer (Thermo Fisher Scientific, Wilmington, USA) was used to determine the concentration of genomic DNA. Gel electrophoresis condition of $1 \%$ agarose gel and $120 \mathrm{~V}$ was used to run the gel for 30 min and subsequent visualization of the DNA fragments.

\subsection{DNA Sequencing and Data Analysis}

The 16S rRNA (V3-V4) hypervariable region of archaea was sequenced using Illumina Hiseq sequencing platform to obtain Paired-ends sequenced. PANDAseq software (Masella et al., 2012) was used to assemble the paired-end reads. Chimera were removed with USEARCH v7.1 (Edgar, 2010) by Denovo method and unique sequences were clustered at 0.03 cutoff ( $97 \%$ similarity) into representative operational taxonomic units (OTUs) using the UPARSE software (Edgar, 2013). Using UCLUST, the representative sequences were compared with the archaea 16S rRNA database of known species to classify each OTU. Alpha and Beta diversity analysis were performed for both treatments and samples using QIIME software. Diversity indices such as observed species, Chaolestimator, Shannon index, and inverse Simpson index were determined. Beta diversity analysis was based on the weighted and unweighted UniFrac evolutionary relationship or distance between species and was used to generate Non Metric Multidimensional Scaling analysis (NMDS) graphs. R statistical package (Kruskal-Wallis test function) was used to analyze Linear Discriminant Analysis Effect Size (LEfSe) to identify significantly (P< 0.05 ) different biomarkers between treatments and the impact on the species or clades with Linear Discriminant Analysis (LDA) score $>3$. Molecular analysis, sequencing reactions and sequence analysis were out sourced in a commercial laboratory (Genepioneer Biotechnologies, Nanjing, China).

SPSS software's (version 19.0; SPSS, Chicago, IL, USA) general linear model function was used to compare means, factor effect and interaction of factors on microbial diversity indices and their significant differences. Post Hoc analysis was tested by Tukey's HSD Test $(\mathrm{P}<0.05)$.

\section{Results}

A range of 11,093-20,601 clean tags were obtained per sample for archaea and bacterial 16S rRNA genes through sequence optimization and quality filtering. At 0.03 similarity cutoff $(97 \%)$, a subsample of $11,09316 \mathrm{~S}$ rRNA clean tags gave 51 OTUs out of which 14 OTUs constituted $100 \%$ of the core microbiome in treatment samples. The OTUs were classified into 8 phyla, 8 classes, 8 orders, 5 families, 2 genus and other unidentified taxa at each taxonomic level. 


\subsection{Archaea Diversity and Community Composition}

The dominant Archaea phyla was Crenarchaeota ( $>96 \%$ ) while Euryarchaeota had a lower abundance of $<3 \%$ and Parvarchaeota and other bacteria phyla made up $<1 \%$ across the treatments and depths (Figure 1). The dominant Archaea classes recorded were Thaumarchaeota (phylum Crenarchaeota), Thermoplasmata (phylum Euryarchaeota) and Parvarchaea, order level; Nitrososphaerales (phylum Crenarchaeota), family level; Nitrososphaeraceae and genus level; Candidatus Nitrososphaera (Figure 1). However, the abundance of Crenarchaeota (phylum to genus) was averagely higher $(>98 \%)$ in the $0-10 \mathrm{~cm}$ soil depth than $10-30 \mathrm{~cm}$ across the treatments.

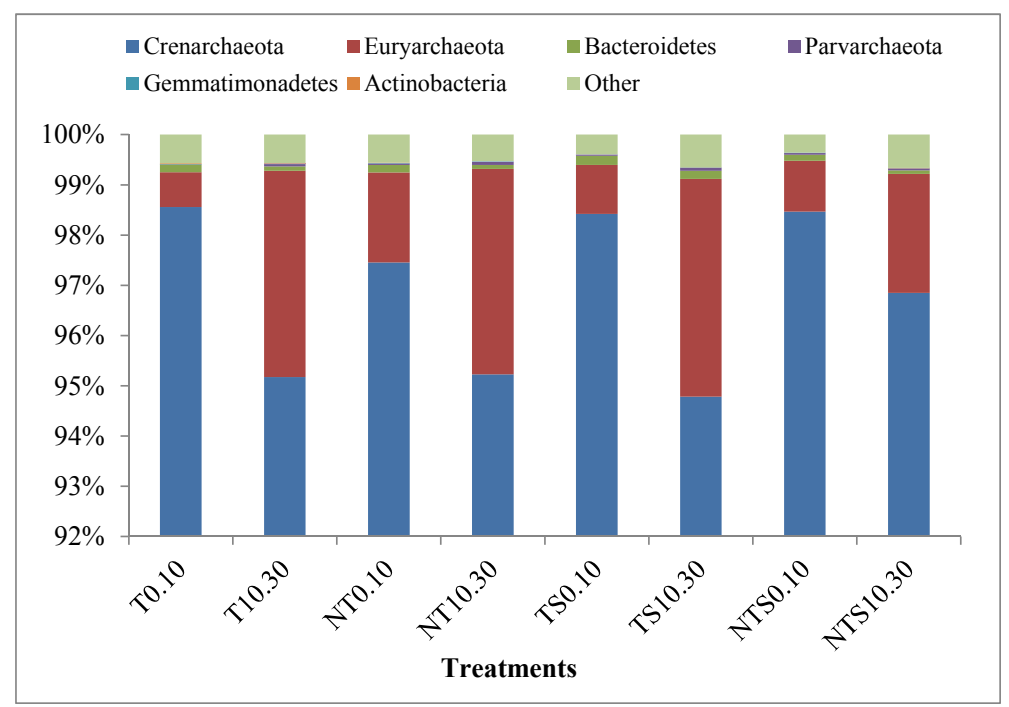

Figure 1. Phylum level OTU abundance profile of archaea and bacteria 16s rRNA genes

Note. T: Conventional tillage with stubble removed; NT: No-tillage with stubble removed; NTS: No-tillage with stubble retained; TS: Conventional tillage with stubble incorporated. 0.10: soil depth of 0-10 cm; 10.30: soil depth of $10-30 \mathrm{~cm}$.

\subsection{LEfSe Analysis of Significantly Enriched Archaea Communities in Treatments}

LEfSe analysis was used to identify significantly $(\mathrm{p}<0.05)$ abundant and enriched microbial communities with LDA score $>3$ in treatments and was presented from domain to genus levels (Figures $2 \mathrm{a}$ and $2 \mathrm{~b}$ ). Enriched microbial communities were only recorded in the two treatments of conventional tillage (T and TS). In the conventional tillage with stubble removed (T), Crenarchaeota (phylum to genus); Thaumarchaeota, Nitrososphaerales, Nitrososphaeraceae, Candidatus Nitrososphaera were enriched in the 0-10 $\mathrm{cm}$ soil layer. However, conventional tillage with stubble incorporated (TS) during ploughing enriched members of the phylum Euryarchaeota and class Thermoplasmata in the 10-30 cm layer. 


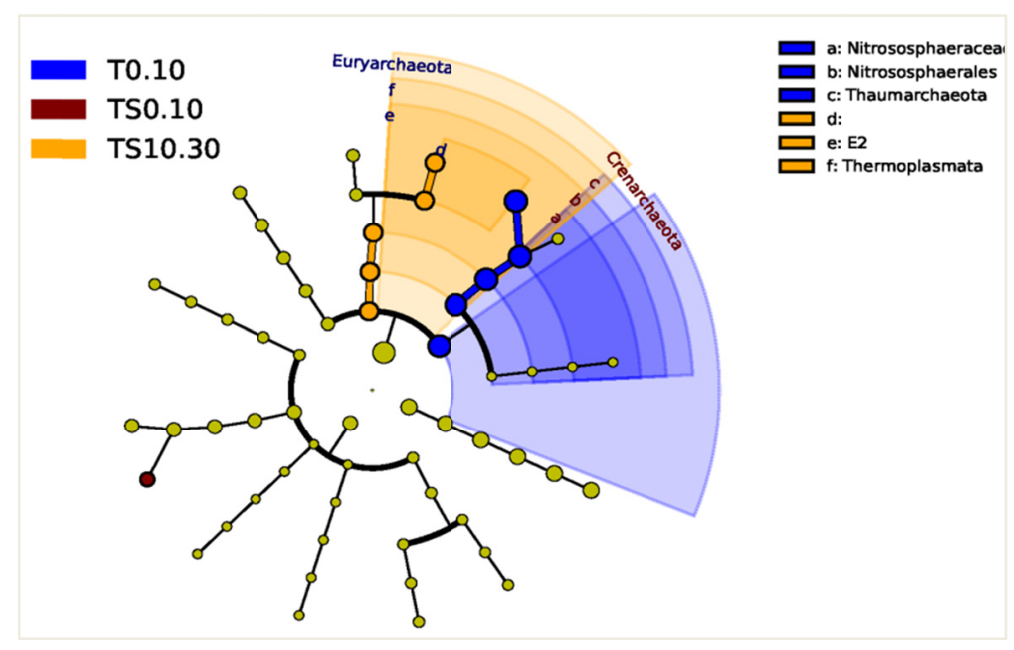

(a)

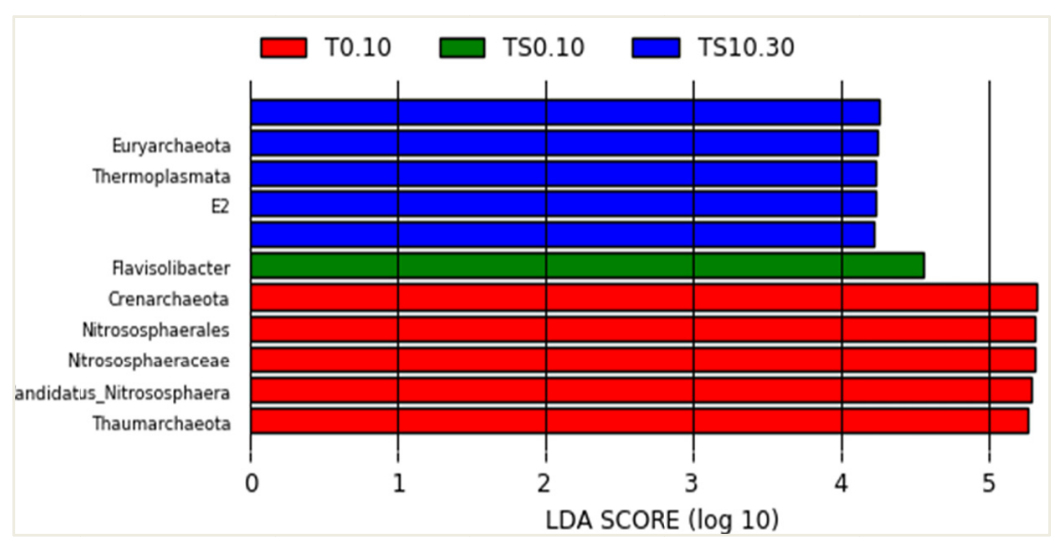

(b)

Figure 2. Cladogram showing the phylogenetic distribution of the Archaea associated with soil under different tillage treatments (a). Circles indicate clades from domain to genus and diameter of each circle is proportional to the abundance. Significantly enriched Archaea with LDA scores $>3$ in Archaea communities associated with soil under different tillage treatments (b)

Note. TS: Conventional tillage with stubble incorporated; T: Conventional tillage with stubble removed; NTS: No-tillage with stubble retained. 0.10: soil depth of 0-10 cm; 10.30: soil depth of 10-30 cm.

\subsection{Effect of Tillage Systems on Archaea Diversity}

Generally at the $0-10 \mathrm{~cm}$ soil depth, treatment means ranked as NT $>$ NTS $>$ TS $>$ T for the various diversity indices calculated for 16S rRNA genes (Table 2). Analysis of factor effect revealed that tillage but not stubble retention or their interaction significantly influenced $(\mathrm{P}<0.01$ and $\mathrm{P}<0.05) 16 \mathrm{~S}$ rRNA number of OTUs, Shannon and Simpson indices in the $0-10 \mathrm{~cm}$ topsoil (Table 2). Again, tillage effect significantly $(\mathrm{P}<0.01)$ influenced Simpson index at $10-30 \mathrm{~cm}$ depth. At the $0-10 \mathrm{~cm}$ soil depth, significant differences $(\mathrm{P}<0.05)$ were recorded for number of OTUs, Shannon index and Inverse Simpson index but Chao1 estimator and number of observed species were only numerically high for NT. At 10-30 cm depth, higher diversity indices were recorded than in the $0-10 \mathrm{~cm}$ but only Simpson evenness index recorded significant differences with NTS recording the highest mean. Species diversity was relatively low (2.3-2.6), however evenness $(0.746-0.789)$ of the microbial community was recorded across the treatments (Table 2). 
Table 2. Diversity indices analysis of soil Archaea and Bacteria 16S rRNA communities under different tillage and stubble treatments at soil depths of $0-10 \mathrm{~cm}$ and $10-30 \mathrm{~cm}$

\begin{tabular}{|c|c|c|c|c|c|c|c|}
\hline Soil depth & Treatments & $\begin{array}{l}\text { Number of } \\
\text { OTUs }\end{array}$ & Chao1 & $\begin{array}{l}\text { Good } \\
\text { Coverage }\end{array}$ & $\begin{array}{l}\text { Observed } \\
\text { Species }\end{array}$ & $\begin{array}{l}\text { Shannon } \\
\text { Index }\end{array}$ & $\begin{array}{l}\text { Simpson } \\
\text { Index }\end{array}$ \\
\hline \multirow[t]{6}{*}{$0-10 \mathrm{~cm}$} & $\mathrm{~T}$ & $55.7 \mathrm{a}$ & $65.6 \mathrm{a}$ & $0.998 \mathrm{a}$ & $45.7 \mathrm{a}$ & $2.3 \mathrm{a}$ & $0.746 \mathrm{a}$ \\
\hline & NT & $84.0 \mathrm{~b}$ & $110.6 \mathrm{a}$ & $0.997 \mathrm{a}$ & $65.0 \mathrm{a}$ & $2.6 \mathrm{~b}$ & $0.789 b$ \\
\hline & TS & $61.7 \mathrm{ab}$ & $92.8 \mathrm{a}$ & $0.998 \mathrm{a}$ & $49.7 \mathrm{a}$ & $2.4 \mathrm{ab}$ & $0.765 \mathrm{ab}$ \\
\hline & NTS & $67.7 \mathrm{ab}$ & $111.3 \mathrm{a}$ & $0.998 \mathrm{a}$ & $49.7 \mathrm{a}$ & $2.5 \mathrm{ab}$ & $0.785 \mathrm{ab}$ \\
\hline & $\mathrm{T}$ & $*$ & ns & - & ns & $*$ & $* *$ \\
\hline & $\mathrm{S}$ and $\mathrm{T} * \mathrm{~S}$ & ns & ns & - & ns & ns & $\mathrm{ns}$ \\
\hline \multirow[t]{6}{*}{$10-30 \mathrm{~cm}$} & $\mathrm{~T}$ & $79.0 \mathrm{a}$ & $94.5 \mathrm{a}$ & $0.998 \mathrm{a}$ & $55.7 \mathrm{a}$ & $2.5 \mathrm{a}$ & $0.765 \mathrm{a}$ \\
\hline & NT & $79.7 \mathrm{a}$ & $109.4 \mathrm{a}$ & $0.997 \mathrm{a}$ & $63.7 \mathrm{a}$ & $2.6 \mathrm{a}$ & $0.782 \mathrm{ab}$ \\
\hline & TS & $79.0 \mathrm{a}$ & $124.9 \mathrm{a}$ & $0.997 \mathrm{a}$ & $68.7 \mathrm{a}$ & $2.6 \mathrm{a}$ & $0.776 \mathrm{ab}$ \\
\hline & NTS & $84.0 \mathrm{a}$ & $110.6 \mathrm{a}$ & $0.997 \mathrm{a}$ & $65.0 \mathrm{a}$ & $2.6 \mathrm{a}$ & $0.789 b$ \\
\hline & $\mathrm{T}$ & $\mathrm{ns}$ & ns & - & ns & ns & $* *$ \\
\hline & $\mathrm{S}$ and $\mathrm{T}^{*} \mathrm{~S}$ & ns & ns & - & ns & ns & ns \\
\hline
\end{tabular}

Note. Mean values with different letters are significantly different among treatments at $\mathrm{P}<0.05$; $\mathrm{T}$ : Conventional tillage with stubble removed; NT: No-tillage with stubble removed; NTS: No-tillage with stubble retained; TS: Conventional tillage with stubble incorporated; T: tillage effect; $\mathrm{S}$ : stubble effect; $\mathrm{T} * \mathrm{~S}$ : tillage and stubble interaction; *: significant at $\mathrm{P}<0.05 ; * *$ : significant at $\mathrm{P}<0.01$; ns: not significant.

Non Metric Multidimensional Scaling analysis (NMDS) was used to further demonstrate the differences in diversity of species between treatments and the overall microbial community structure. If coordinates of samples are close to each other, then the species composition of the treatments is similar. NMDS clearly grouped the microbial communities according depths but not according to treatments in the present study (Figures 3a and 3b).

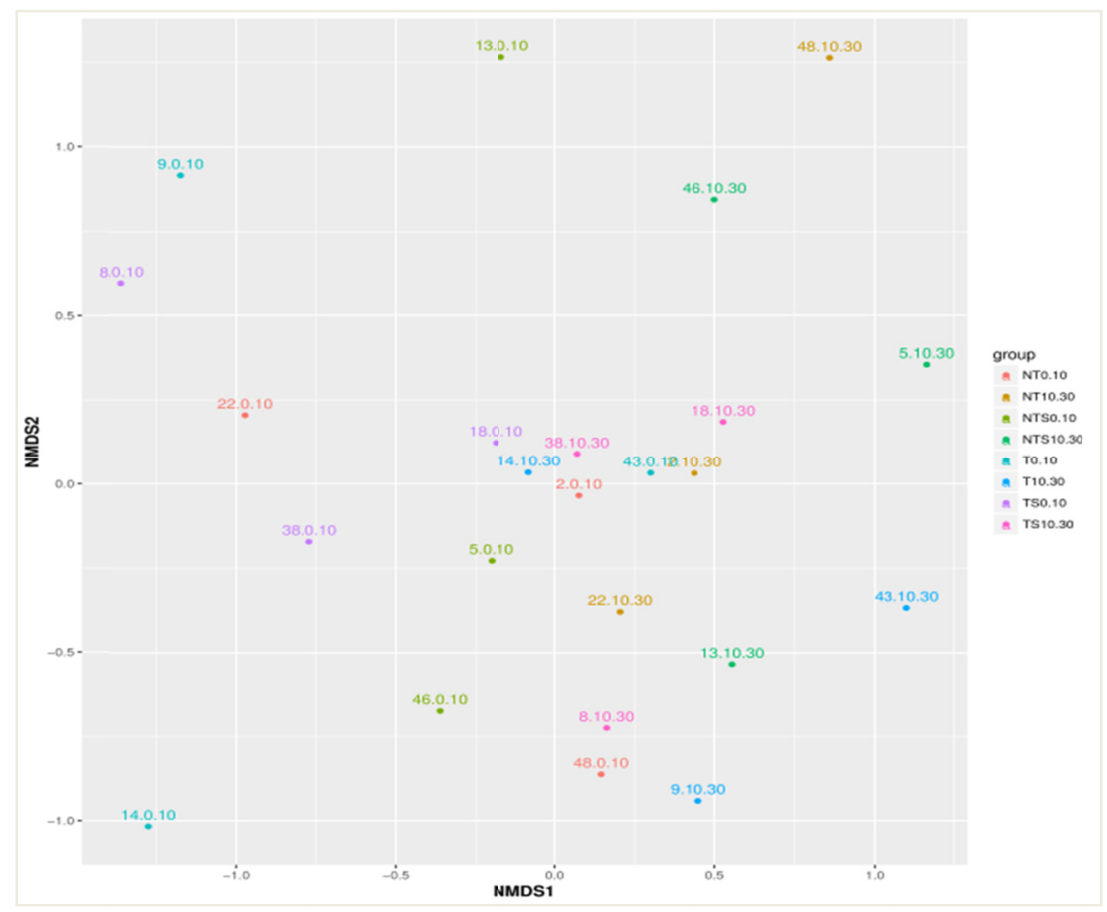

(a) 


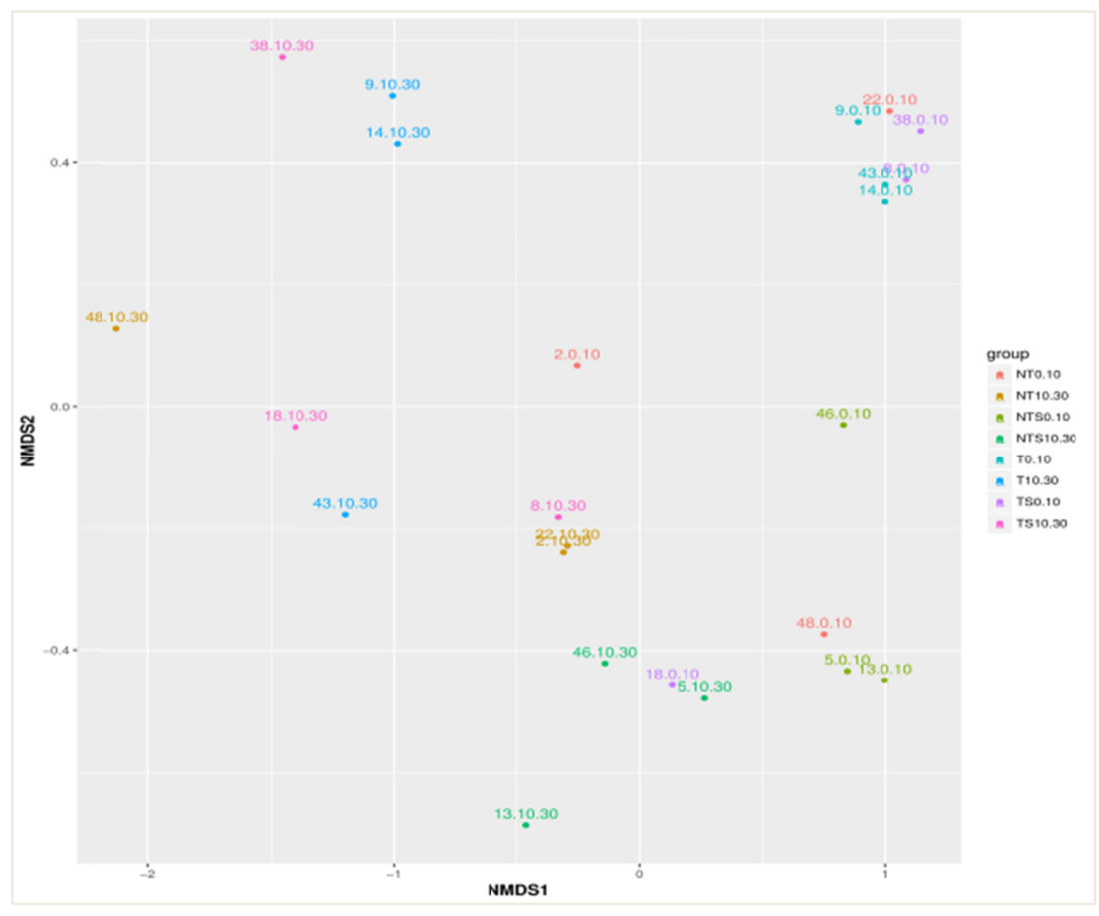

(b)

Figure 3. Unweighted NMDS (a) and Weighted NMDS (b) of Archaea and Bacteria 16S rRNA genes

Note. T: Conventional tillage with stubble removed; NT: No-tillage with stubble removed; NTS: No-tillage with stubble retained; TS: Conventional tillage with stubble incorporated. 0.10 : soil depth of $0-10 \mathrm{~cm} ; 10.30$ : soil depth of $10-30 \mathrm{~cm}$.

\section{Discussion}

Intensification of agriculture has effects on soil microbial communities that are complicated to elucidate, however, attempts to understand them is important for the sustainable use of agricultural fields (Qin et al., 2016). The aim of the study was to investigate the influence of different tillage systems on functional archaea communities in a crop rotation field. The predominant Archaea phyla in the study site was Crenarchaeota and constituted $>96 \%$ of the total abundance. Both conventional (T and TS) and conservational (NT and NTS) tillage treatments consistently recorded high abundance in the $0-10 \mathrm{~cm}$ and $10-30 \mathrm{~cm}$ soil depth but was slightly higher in $0-10 \mathrm{~cm}$ soil layer probably because of the soil disturbance caused by ploughing and archaea are known to be adapted to stress conditions. The occurrence of Crenarchaeota and Euryarchaeota has been demonstrated by $16 \mathrm{~S}$ rRNA gene surveys in non-extreme environments, with Crenarchaeota usually being common in soil environments (Nicol et al., 2003). Hansel et al. (2008) also found members of the Crenarchaeota as the predominant archaeal community in the different soil profile (surface, vadose zone, and saturated soil environments) of their study. Another report described these microbes as ubiquitous and abundant within soils (Ochsenreiter et al., 2003) and may play a critical functional role in terrestrial soils because of their high abundance (Kemnitz et al., 2007). Microbial community structure has been studied and reported to change with soil depth and this is attributable to the different response of microbes to physical, chemical conditions and stresses associated with topsoil and subsurface soils (Holden \& Fierer, 2005). The abundance of Crenarchaeota decreased with depth in our study and these results are similar to Kemnitz et al. (2007) who also recorded decrease in absolute abundance with depth in forest soil. Euryarchaeota is also reported to have been sequenced from barley agricultural field (Ruppel et al., 2007) and the taxon diversity and frequency were found to be lower than that of Crenarchaeota in moderate dry oxic soils (Timonen \& Bomberg, 2009). 'Parvarchaeota' was identified at an extremely low abundance in the weakly alkaline soil of the site and may suggest the isolation of facultative alkaliphile types in the present study. However, 'Parvarchaeota' is known as an acidophilic representative of the DPANN superphylum (Youssef et al., 2015) which was defined from a metagenomic assembly from an acid mine drainage (Baker et al., 2010). 
Crenarchaeota and Thaumarchaeota (previously a class of Crenarchaeota but now a novel phylum) were significantly enriched from phylum to genus in the $0-10 \mathrm{~cm}$ soil layer conventional tillage with stubble removed (T) treatment probably because of the chronic stress imposed by the annual ploughing of this field. The clade Thaumarchaeota predominantly comprise of ammonia oxidizing members (Zhalnina et al., 2012) that carry the amo $A$ genes and oxidize ammonia using ammonia monooxygenase (AMO) enzyme during nitrogen cycling (Taylor et al., 2010; Shen et al., 2013). The other enrichment was detected in the conventional tillage with stubble incorporated (TS) plots at the $10-30 \mathrm{~cm}$ soil layer and the phylum Euryarchaeota and its class Thermoplasmata were the significantly enriched clades. Euryarchaeota constitute a diverse group consisting of extreme halophiles, thermophilic heterotrophs and anaerobic methanogens (Bapteste et al., 2005) that are involved in carbon cycling in their environment. Thermoplasmata is a recently discovered methanogenic class that can reduce methanol with hydrogen (Dridi et al., 2012) and may also use methylamines as substrate for methanogenesis (Poulsen, et al., 2013).

In the present study, the no-tillage systems (NT and NTS) recorded the highest archaea diversity respectively and our findings are congruent with Dorr de Quadros et al. (2012). Also, Dong et al. (2017) have recently reported that NT practices markedly enhanced the abundance of Thaumarchaeota (previously a class of Crenarchaeota but now a novel phylum) in the topsoil after 22 years of no-tillage managements in Northern China. On the contrary, archaea were found not to be affected by the different forms of tillage practices in the experiment conducted by Kaurin et al. (2015) who compared minimum tillage to conventional mouldboard ploughing. In no-tilled soil, physical disturbance is absent hence there is less soil aeration than in tilled soils and this may promote the growth of anaerobic microbes (Dorr de Quadros et al., 2012). Withdrawal of tillage in NT gave significantly high Shannon species diversity index and Inverse Simpson evenness index; however, only numerically high means were obtained for Chaol richness estimator and number of observed species. Irrespective of the tillage practice, the archaea community was evenly distributed but the species diversity was relatively low across the treatments. In the study, treatment influenced clustering of microbial communities by NMDS was not obvious but clear depth wise distribution was observed. This may be explained by complex interaction of factors and mechanism that influence microbial activity and function in agro-ecosystem (Detheridge et al., 2016).

\section{Conclusion}

The dominant archaea phyla identified across the treatments and depths in the study site were Crenarchaeota, Euryarchaeota and Parvarchaeota, with Crenarchaeota making up $>96 \%$ of the total abundance. The treatments ranked as NT $>$ NTS $>$ TS $>$ T for the various diversity indices calculated for $16 \mathrm{~S}$ rRNA genes in the $0-10 \mathrm{~cm}$ topsoil. Factor effect analysis also revealed that tillage significantly influenced archaea diversity in this study. Conventional tillage with stubble removed (T) significantly enhanced the enrichment of Crenarchaeota and Thaumarchaeota in the 0-10 cm soil layer while Euryarchaeota and Thermoplasmata were stimulated in the 10-30 cm layer of tillage with stubble incorporated (TS). No-till promoted even distribution of archaea diversity but $\mathrm{T}$ and TS enriched the archaea clades detected in the study. The study results provide practical implications and benefits for the adoption of conservation tillage practices on soil microbes which are major drivers in the below ground plant-soil ecosystem.

\section{Acknowledgements}

The research is financed by the National Natural Science Foundation of China (31460337, 31660373 and 3171101272), The 'National Twelfth Five-Year Plan' Circular Agricultural Science and Technology Project (2012 BAD14B03), Education Department of Gansu Province (2017C-12) and Gansu Provincial Key Laboratory of Aridland Crop Science open fund project (GSCS-2013-13). We also appreciate assistance in the field and laboratory by students of the Gansu Agricultural University Dingxi Long-term Rainfed Agricultural Experimental Station.

\section{References}

Baker, B. J., Comolli, L. R., Dick, G. J., Hauser, L. J., Hyatt, D., Dill, B. D., ... Banfield, J. F. (2010). Enigmatic, ultrasmall, uncultivated Archaea. Proceedings of the National Academy of Sciences of the United States of America, 107(19), 8806-8811. https://doi.org/10.1073/pnas.0914470107

Bapteste, E., Brochier, C., \& Boucher, Y. (2005). Higher-level classification of the Archaea: Evolution of methanogenesis and methanogens. Archaea, 1, 353-363. http://dx.doi.org/10.1155/2005/859728 
Case, R. J., Boucher, Y., DahllöI, F., Holmström, C., Doolittle, W. F., \& Kjelleberg, S. (2007). Use of 16S rRNA andrpoBGenes as MolecularMarkersfor Microbial Ecology Studies. Applied and Environmental Microbiology, 73(1), 278-288. https://doi.org/10.1128/AEM.01177-06

Chinese Soil Taxonomy Cooperative Research Group. (1995). Chinese Soil Taxonomy (Revised Proposal). Beijing, China: Institute of Soil Science/Chinese Agricultural Science and Technology Press, Academic Sinica.

Detheridge, A. P., Brand, G., Fychan, R., Crotty, F. V., Sanderson, R., Griffith, G. W., \& Marley, C. L. (2016). The legacy effect of cover crops on soil fungal populations in a cereal rotation. Agriculture, Ecosystems and Environment, 228, 49-6. https://doi.org/10.1016/j.agee.2016.04.022

Dong, W., Liu, E., Yan, C., Zhang, H., \& Zhang, Y. (2017). Changes in the composition and diversity of topsoil bacterial, archaeal and fungal communities after 22 years conventional and no-tillage managements in Northern China. Archives of Agronomy and Soil Science, 63(10). https://doi.org/10.1080/03650340. 2017.1281392

Dorr de Quadros, P., Zhalnina, K., Davis-Richardson, A., Fagen, J. R., Drew, J., Bayer, C., Camargo, F. A. O., \& Triplett, E. W. (2012). The Effect of Tillage System and Crop Rotation on Soil Microbial Diversity and Composition in a Subtropical Acrisol. Diversity, 4, 375-395. https://doi.org/10.3390/d4040375

Dridi, B., Fardeau, M. L, Ollivier, B., Raoult, D., \& Drancourt, M. (2012). Methanomassiliicoccus luminyensis gen. nov., sp. nov., a methanogenic archaeon isolated from human faeces. International Journal of Systematic and Evolutionary Microbiology, 62, 1902-1907. https://doi.org/10.1099/ijs.0.033712-0

Edgar, R. C. (2010). Search and clustering orders of magnitude faster than BLAST. Bioinformatics, 26, 2460-2461. https://doi.org/10.1093/bioinformatics/btq461

Edgar, R. C. (2013). UPARSE: Highly accurate OTU sequences from microbial amplicon reads. Nature Methods, 10, 996-998. https://doi.org/10.1038/nmeth.2604

Fan, T. L., Stewart, B. A., Wang, Y., Luo, J. J., \& Zhou G. Y. (2005). Long-term fertilization effects on grain yield, water-use efficiency and soil fertility in the dryland of Loess Plateau in China. Agriculture, Ecosystems and Environment, 106, 313-329. https://doi.org/ 10.1016/j.agee.2004.09.003

Feng, Y., Motta, A. C., Reeves, D. W., Burmester, C. H., van Santen, E., \& Osborne, J. A. (2003). Soil microbial communities under conventional-till and no-till continuous cotton systems. Soil Biology and Biochemistry, 35, 1693-1703. https://doi.org/10.1016/j.soilbio.2003.08.016

Food and Agriculture Organisation. (1990). Soil map of the world: Revised legend. World Soil Resources Report, 60. Rome: Food and Agriculture Organization of the United Nations.

Hansel, C. M., Fendorf, S., Jardine, P. M., \& Francis, C. A. (2008). Changes in Bacterial and Archaeal Community Structure and Functional Diversity along a Geochemically Variable Soil Profile. Applied and Environmental Microbiology, 74(5), 1620-1633. https://doi.org/10.1128/AEM.01787-07

Holden, P. A., \& Fierer. N. (2005). Microbial processes in the vadose zone. Vadose Zone Journal, 4, 1-21. https://doi.org/10.2136/vzj2005.0001

Huang, M., Jiang, L., Zou, Y., Xu, S., \& Deng, G. (2013). Changes in soil microbial properties with no-tillage in Chinese cropping systems. Biology and Fertility of Soils, 49, 373-377. https://doi.org/10.1007/ s00374-013-0778-6

Jarrell, K. F, Walters, A. D., Bochiwa, C., Borgia, J. M., Dickinson, T., \& Chong, J. P. J. (2011). Major players on the microbial stage: Why archaea are important. Microbiology, 157, 919-936. https://doi.org/10.1099/ mic.0.047837-0

Kaurin, A., Mihelič, R., Kastelec, D., Schloter, M., Suhadolc, M., \& Grčman, H. (2015). Consequences of minimum soil tillage on abiotic soil properties and composition of microbial communities in a shallow Cambisol originated from fluvioglacial deposits. Biology and Fertility of Soils, 51, 923-933. https://doi.org/10.1007/s00374-015-1037-9

Kemnitz, D., Kolb, S., \& Conrad, R. (2007). High abundance of Crenarchaeota in a temperate acidic forest soil. FEMS Microbiology Ecology, 60, 442-448. https://doi.org/10.1111/j.1574-6941.2007.00310.x

Klingler, J. M., Stowe, R. P., Obenhuber, D. C., Groves, T. O., Mishra, S. K., \& Pierson, D. L. (1992). Evaluation of the Biolog automated microbial identification system. Applied and Environmental Microbiology, 58, 2089-2092. 
Lamptey, S., Li, L., Xie, J., Zhang, R., Luo, Z., Cai, L., \& Liu, J. (2017). Soil respiration and net ecosystem production under different tillage practices in semi-arid Northwest China. Plant Soil and Environment, 63, 14-21. https://doi.org/10.17221/403/2016-PSE

Masella, A. P., Bartram, A. K., Truszkowski, J. M., Daniel, G., \& Neufeld, J. D. B. (2012). PANDAseq: Paired-end assembler for illumina sequences. BMC Bioinformatics, 13(31), 1-7. https://doi.org/10.1186/ 1471-2105-13-31

Navarrete, A. A., Taketani, R. G., Mendes, L. W., Cannavan, F. S., Moreira, F. M. S., \& Tsai, S. M. (2011). Land-use systems affect archaeal community Structure and functional diversity in Western amazon soils. Revista Brasileira de Ciência do Solo, 35, 1527-1540. https://doi.org/10.1590/S0100-06832011000500007

Ng, J. P., Hollister, E. B., González-Chávez, M. C. A., Hons, F. M., Zuberer, D. A., Aitkenhead-Peterson, J. A., ... Gentry, T. J. (2012). Impacts of Cropping Systems and Long-Term Tillage on Soil Microbial Population Levels and Community Composition in Dryland Agricultural Setting. International Scholarly Research Notices Ecology, 2012(487370), 1-11. https://doi.org/10.5402/2012/487370

Nicol, G. W., Glover, L. A., \& Prosser, J. I. (2003). Spatial analysis of archaeal community structure in grassland soil. Applied and Environmental Microbiology, 69, 7420-7429. https://doi.org/10.1128/AEM.69.12.74207429.2003

Nolan, S., Unkovich, M., Shen, Y., Li, L., \& Bellotti, W. (2008). Farming systems of the Loess Plateau, Gansu Province, China. Agriculture, Ecosystems and Environment, 124, 13-23. https://doi.org/10.1016/j.agee. 2007.08.009

Ochsenreiter, T., Selezi, D., Quaiser, A., Bonch-Osmolovskaya, L., \& Schleper, C. (2003). Diversity and abundance of Crenarchaeota in terrestrial habitats studied by 16S RNA surveys and real time PCR. Environmental Microbiology, 5, 787-797. https://doi.org/10.1046/j.1462-2920.2003.00476.x

Offre, P., Spang, A., \& Schleper, C. (2013). Archaea in Biogeochemical Cycles. Annual Review of Microbiology, 67, 437-57. https://doi.org/10.1146/annurev-micro-092412-155614

Poulsen, M., Schwab, C., Jensen, B. B., Engberg, R. M., Spang, A., Canibe, N., ... Urich, T. (2013). Methylotrophic methanogenic Thermoplasmata implicated in reduced methane emissions from bovine rumen. Nature Communications, 4(1428), 1-7. https://doi.org/10.1038/ncomms2432

Pratscher, J., Dumont, M. G., \& Conrad, R. (2011). Ammonia oxidation coupled to $\mathrm{CO}_{2}$ fixation by archaea and bacteria in an agricultural soil. Proceedings of the National Academy of Sciences of the United States of America, 108(10), 4170-4175. https://doi.org/10.1073/pnas.1010981108

Qin, S., Yeboah, S., Wang, D., \& Zhang, J. (2016). Effects of ridge-furrow and plastic mulching planting patterns on microflora and potato tuber yield in continuous cropping soil. Soil Use and Management, 32, 465-473. https://doi.org/10.1111/sum.12291

Ruppel, S., Torsvik, V., Daae, F., Ovreas, L., \& Ruhlmann, J. (2007). Nitrogen availability decreases prokaryotic diversity in sandy soils. Biology and Fertility of Soils, 43, 449-459. https://oi.org/10.1007/s00374006-0122-5

Shen, J. P., Cao, P., Hu, H. W., \& He, J. Z. (2013). Differential response of archaeal groups to land use change in an acidic red soil. Science of the Total Environment, 461-462, 742-749. https://doi.org/10.1016/j.scitotenv. 2013.05.070

Swan, B. K., \& Valentine, D. L. (2009). Diversity of Archaea. Encyclopedia of Life Sciences eLS. John Wiley \& Sons, Ltd. https://doi.org/10.1002/9780470015902.a0000444.pub2

Taylor, A. E., Zeglin, L. H., Dooley, S., Myrold, D. D., \& Bottomley, P. J. (2010). Evidence for Different Contributions of Archaea and Bacteria to the Ammonia-Oxidizing Potential of Diverse Oregon Soils. Applied and Environmental Microbiology, 76(23), 7691-7698. https://doi.org/10.1128/AEM.01324-10

Timonen, S., \& Bomberg, M. (2009). Archaea in dry soil environments. Phytochemistry Reviews, 8, 505-518. https://doi.org/10.1007/s11101-009-9137-5

Vos, M., Quince, C., Pijl, A. S., de Hollander, M., \& Kowalchuk, G. A. (2012). A Comparison of rpoB and 16S rRNA as Markers in Pyrosequencing Studies of Bacterial Diversity. PLoS ONE, 7(2), e30600. https://doi.org/10.1371/journal.pone.0030600 
Yeboah, S., Lamptey, S., Zhang, R., \& Li, L. (2017). Conservation Tillage Practices Optimizes Root Distribution and Straw Yield of Spring Wheat and Field Pea in Dry Areas. Journal of Agricultural Science, 9(6), 37-48. https://doi.org/10.5539/jas.v9n6p37

Yeboah, S., Zhang, R., Cai, L., Li, L., Xie, J., Luo, Z., ... Wu, J. (2016a). Tillage effect on soil organic carbon, microbial biomass carbon and crop yield in spring wheat-field pea rotation. Plant, Soil and Environment, 62(6), 279-28. https://doi.org/10.17221/66/2016-PSE

Yeboah, S., Zhang, R., Cai, L., Song, M., Li, L., Xie, J., ... Wu, J. (2016b). Greenhouse gas emissions in a spring wheat-field pea sequence under different tillage practices in semi-arid Northwest China. Nutrient Cycling in Agroecosystems, 106, 77-91. https://doi.org/10.1007/s10705-016-9790-1

Youssef, N. H., Rinke, C., Stepanauskas, R., Farag, I., Woyke, T., \& Elshahed, M. S. (2015). Insights into the metabolism, lifestyle and putative evolutionary history of the novel archaeal phylum 'Diapherotrites'. International Society for Microbial Ecology Journal, 9, 447-460. https://doi.org/10.1038/ismej.2014.141

Zhalnina, K., de Quadros, P. D., Camargo, F. A. O., \& Triplett, E. W. (2012). Drivers of archaeal ammonia-oxidizing communities in soil. Frontiers in Microbiology, 3(210), 1-9. https://doi.org/10.3389/ fmicb.2012.00210

Zhang, D., Yao, P., Na, Z., Cao, W., Zhang, S., Li, Y., \& Gao, Y. (2016). Soil Water Balance and Water Use Efficiency of Dryland Wheat in Different Precipitation Years in Response to Green Manure Approach. Scientific Reports, 6(26856), 1-12. https://doi.org/10.1038/srep26856

\section{Copyrights}

Copyright for this article is retained by the author(s), with first publication rights granted to the journal.

This is an open-access article distributed under the terms and conditions of the Creative Commons Attribution license (http://creativecommons.org/licenses/by/4.0/). 